\title{
HARMONIC REDUCTION AND POWER FACTOR REGULATION FOR THREE-PHASE PWM BOOST RECTIFIER
}

\author{
E. E. EL-Kholy A. El-Hefnawy Hamdy M. Mahrous \\ Electrical Engineering Department, Faculty of Engineering, Shebin El-Kom, \\ Minoufiya University, Egypt
}

\begin{abstract}
Due to the enhancement in high-speed switching semiconductor devices, the employ of threephase PWM boost rectifier (BR) has grown to be more common in the past decade. The PWM rectifier can provide input currents without distortion and with unity power factor at the supply terminals. The description and modeling of the three-phase PWM rectifier have been analyzed using the voltage source inverter (VSI) with resistive load. The proposed control scheme in this paper has two closed loops to compute the three-phase reference currents of PWM rectifier. The first, namely dc load current loop, and the second, using dc bus voltage loop. The unity power factor and reduction of pollution harmonic is completely fulfilled with current controller that is applied linear current controller. The Simulation and experimental results verify the operational characteristics of the PWM rectifier.

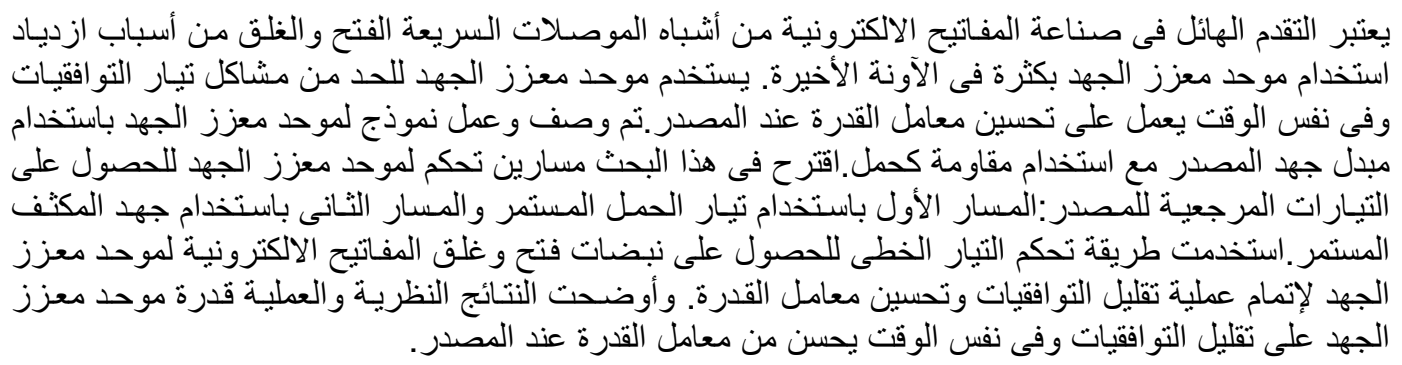

Keywords: Boost rectifier, voltage source inverter (VSI), dc load current loop, harmonic reduction

\section{INTRODUCTION}

As it has been observed for recent decades, an increasing part of the generated electric energy is converted through rectifiers, before it is used at the final load. In power electronic systems, especially, diode and thyristor rectifiers are commonly applied in the front end of DC-link power converters. The rectifiers are nonlinear in nature and, consequently, generate harmonic currents in to the $\mathrm{AC}$ line power. The high harmonic content of the line current and the resulting low power factor of the load, causes a number of problems in the power distribution system [1] like:

1-Voltage distortion and electromagnetic interface (EMI) affecting other users of the power system.

2-Increasing voltampere ratings of the power system equipment (generators, transformers, transmission lines, etc.).

These problems have become a major concern nowadays, and the research and developed effects are thus being concentrated on the solutions by which distortion influences can be eliminated or reduced significantly. The passive filters used for input current shaping provide a limited range of harmonic compensation with varying load [2]. One of the potential solutions to cancel the harmonics from the entering of power system is by three-phase PWM rectifier. The most interesting feature of this PWM rectifier, however, is not the unity power factor or the boost output voltage, but the bi-directional energy flow capability [3]. To control this system, many control strategies have been proposed recently [1-11]. The conventional algorithm (i.e.PI) to control these systems suffer from the problem, in that they are tuned if any of the system parameters change, [4]. Moreover, conventional control methods for PWM rectifier, which depending on $P I$ regulators for the output voltage, still are dependent on the load and the switching frequency. Also these types of conventional control give rise times and damping factors depending on the rectifier operating point [5]. So, in this paper, a new control strategy, which based on two closed loops; dc load current loop, beside, dc bus voltage loop with PI controller has been proposed to reduce the harmonics and power factor regulation of the PWM rectifier. The current controller technique, which discussed in this paper, is based on linear current regulator. In this controller the feedback of current always follows its reference. 


\section{DESCRIPTION, OPERATION AND MODELING OF THE THREE-PHASE PWM RECTIFIER}

\subsection{Description of the Three-Phase PWM Rectifier}

The main circuit of the three-phase PWM rectifier is shown in Fig.1. It basically consists of six switches (IGBT anti-parallel with diodes); three boost inductors $\left(L_{s}\right)$, the output capacitor $(C)$ and variable resistance $(R)$ as a resistive load. The supply voltage supplies power to the load through the full-bridge converter. This construction of the three-phase PWM rectifier as a voltage source inverter VSI, combination with the load, consider as a nonlinear load in respect to the AC supply. The line inductors $\left(L_{s}\right)$ decouple the supply voltage from the converter's ac terminals, while providing the input current source characteristic and limiting the input current distortion [7]. The capacitor $(C)$ provides the output voltage characteristic, and stores the energy required to satisfied purpose of reducing the supply current harmonic and improve the power factor.

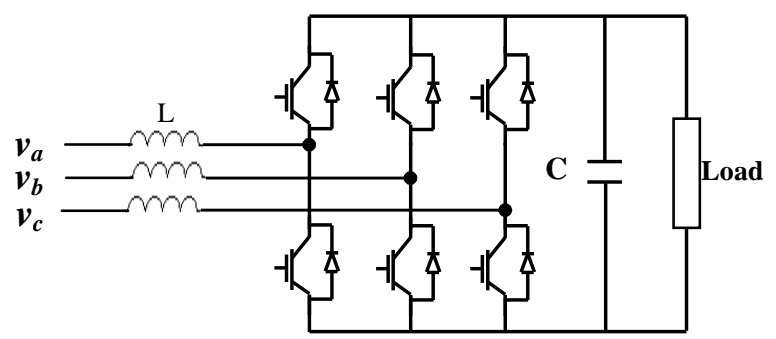

Fig.1 Main circuit of the Three-Phase PWM Rectifier

\subsection{Operation Principle}

The basic operation principle of the PWM rectifier is analogous to that of the boost dc chopper, that is, during the AC side by-pass of the current source rectifier, the source energy is accumulated in the inductor, and then, by switching of the current source rectifier, this energy is expelled to the DC side resulting in boost effect. But the PWM rectifier has another control object; the unity power factor, harmonic reduction at input $\mathrm{AC}$ side, besides the boost output voltage.

\subsection{Modeling of the Three-Phase PWM Rectifier}

The principal simulation model of three-phase PWM rectifier that illustrated in Fig. 2 can be represented as a state (1 or 0 ) of bi-directional switches (IGBTs), by introducing the converter functions $N A, N B$ and $N C$ for the three legs of PWM rectifier.

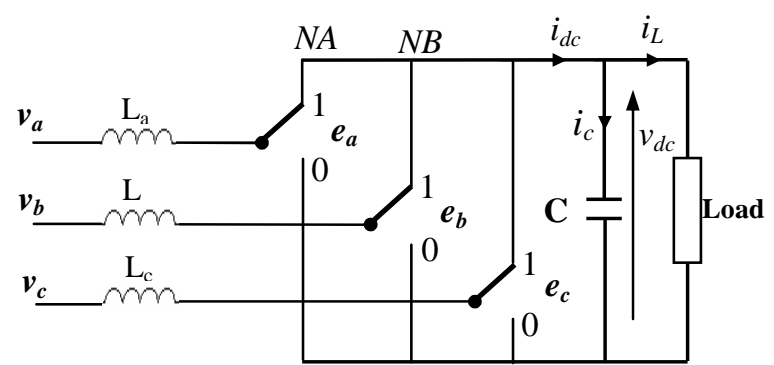

Fig.2 Three-Phase PWM Rectifier modeling

The equations, which are coupled the three- phase AC side with DC side of PWM rectifier as shown in Fig.2, are deduced as follows:

The voltages $\left(e_{a}, e_{b}, e_{c}\right)$ as a function in dc side voltage and the converter functions can be written as Eq. (1):

$$
\left[\begin{array}{l}
e_{c} \\
e_{b} \\
e_{c}
\end{array}\right]=\left[\begin{array}{l}
f_{1} \\
f_{2} \\
f_{3}
\end{array}\right] V_{d e}
$$

Where

$$
\begin{aligned}
& f_{1}=\frac{2 N A-N B-N C}{3} \\
& f_{2}=\frac{2 N B-N C-N A}{3} \\
& f_{3}=\frac{2 N C-N A-N B}{3}
\end{aligned}
$$

The dc current $i_{d c}$ as a function with line currents $\left(i_{a}\right.$, $\left.i_{b}, i_{c}\right)$ is defined as: Eq. (2):

$$
i_{d o}=\left[\begin{array}{lll}
N A & N B & N C
\end{array}\right]\left[\begin{array}{l}
i_{a} \\
i_{b} \\
i_{c}
\end{array}\right]
$$

The output dc bus voltage equal as Eq.(3):

$$
\begin{aligned}
V_{\text {dic }} & =-\frac{1}{C} \int i_{C} d t \\
& =-\frac{1}{C} \int\left(i_{d c}-i_{L}\right) d t
\end{aligned}
$$

The line current in ac side can be deduced from the Eqs. (4) as follows:

$$
\begin{aligned}
& v_{a}-e_{a}=L_{a} \frac{d i_{a}}{d t} \\
& v_{b}-e_{b}=L_{b} \frac{d i_{b}}{d t} \\
& v_{c}-e_{C}=L_{C} \frac{d i_{C}}{d t}
\end{aligned}
$$




\section{LAYOUT CONTROL OF THE PWM RECTIFIER}

The layout of control of PWM rectifier that shown in Fig. 3 is contain two units. This control techniques are combined and has two-closed loop namely, dc load current loop and dc bus voltage loop.

\subsection{Load Current Loop}

As shown in Fig.3, the dc load current loop maintains a proper balance in power flow from input port to output port of the PWM rectifier. During the load change on PWM rectifier from one value to another, the dc load current loop provides instantaneous information to control structure of the PWM rectifier. With the knowledge output load conditions the dc load current loop makes the one component of computation the three-phase reference currents at the input of PWM rectifier. To implement dc load current loop, the dc load current $\left(i_{L}\right)$ is sensed and passed through a low pass filter to get rid off high frequency ripples in the load current. The output of the low pass filter $\left(I_{P 1}\right)$ is considered a first component of the magnitude of three-phase reference currents at the input port of the PWM rectifier.

\subsection{Bus Voltage Loop}

The second loop as illustrated in Fig.3 is dc bus voltage loop with PI controller. The output dc voltage $V_{d c}$ is compared with its reference voltage $V_{d c}{ }^{*}$, and the error is fed to a $P I$ regulator to reduce the steady state error and keeps the dc output voltage constant. The output of $P I$ controller is input to a limiter and output of limiter $\left(I_{P 2}\right)$ is considered as second component (magnitude) of computation the three-phase reference currents at the input of PWM rectifier. The component $\left(I_{p 2}\right)$ keeps the dc bus voltage of PWM rectifier close to the set values $V_{d c}^{*}$.

\subsection{Reference Current Determination}

To compute the three-phase reference currents at the input of the PWM rectifier, the dc load current loops and the output of the dc bus voltage are used. Therefore, the magnitude $\left(I_{P}\right)$ of three-phase reference currents is expressed as;

$$
I_{P}=I_{P 1}+I_{P 2}
$$

Where $I_{P 2}$ regulates the dc load voltage close to its set value $\left(V^{*}{ }_{d c}\right)$. Whereas, $I_{P I}$ balances the power flow from input port to output port of the PWM rectifier and this is according to the need of load power at output port of PWM rectifier. On the other side, the phases of three-phase reference currents are computed from the supply voltages and the amplitude of rms supply voltages $\left(V_{P}\right)$, which is calculated from the source phase voltages $v_{a}, v_{b}$ and $v_{c}$ as expressed in (6).

$$
V_{p}=\sqrt{\frac{2\left(v_{a}^{2}+v_{b}^{2}+v_{c}^{2}\right)}{3}}
$$

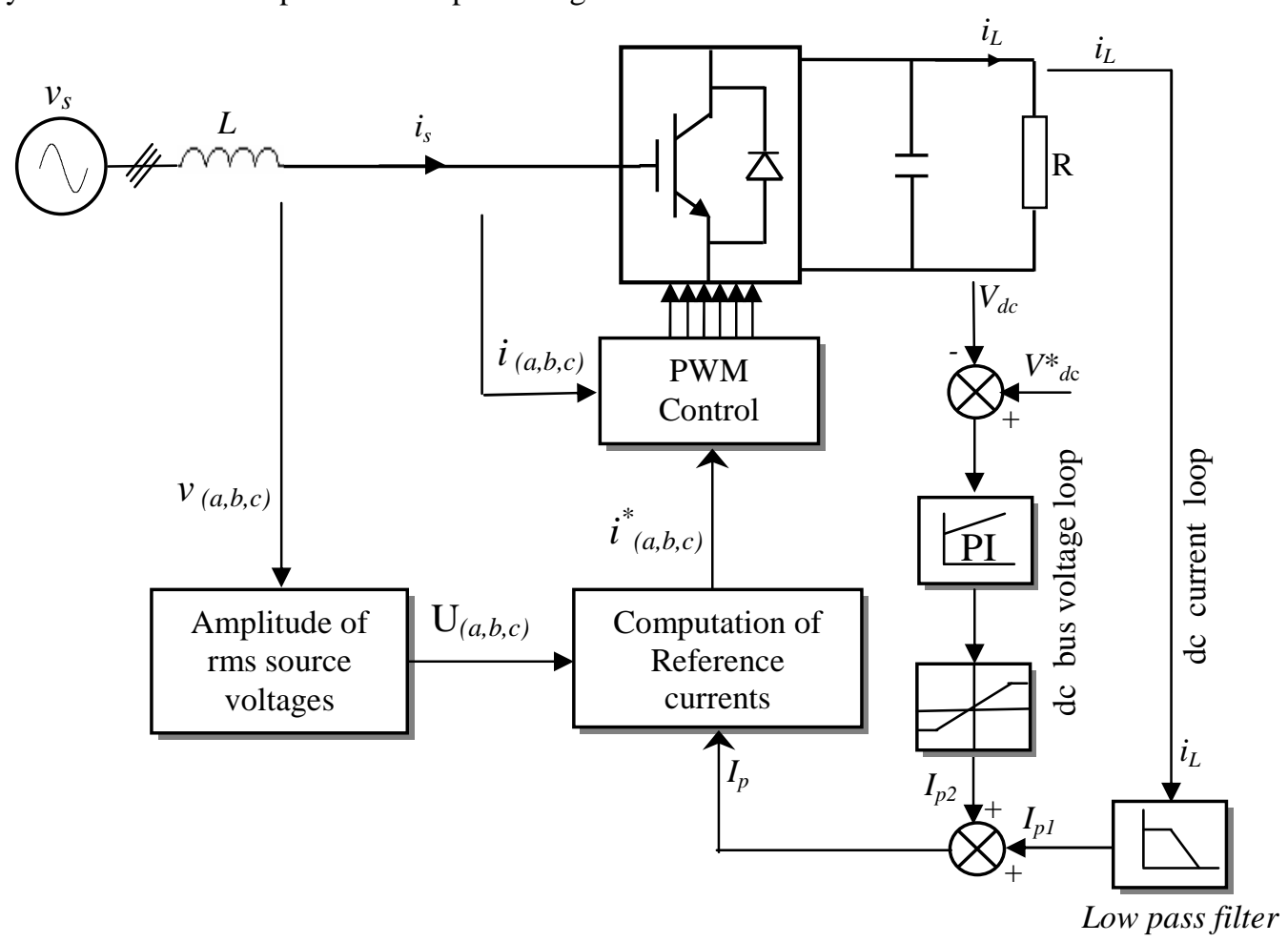

Fig.3 The layout of control of PWM Boost Rectifier 
Then, the phases of three-phase reference currents $\left(U_{a}, U_{b}\right.$ and $\left.U_{c}\right)$ is obtained as:

$U_{a}=V_{a} / V_{P}$

$U_{b}=V_{b} / V_{P}$

$U_{a}=V_{c} / V_{P}$

The three-phase reference currents are then computed as follows:

$i_{a}^{*}=U_{a} I_{P}$

$i_{b}^{*}=U_{b} I_{P}$

$i_{c}^{*}=U_{c} I_{P}$

\subsection{Modulation Technique}

In the modulation stage (Fig.4), comparison of threephase reference currents $\left(i_{a}^{*}, i_{b}^{*}, i_{c}^{*}\right)$ with sensed current $\left(i_{a}, i_{b}, i_{c}\right)$, obtaining a current error adapted according to the amplitude of the triangular carrier. The purpose of introducing the triangular waveform is to stabilize the converter switching frequency by forcing it to be constant and equal to the frequency of the triangular reference signal. Since the current error signal is always kept within in the negative and positive peaks of the triangular waveform, the system has an inherent over current protection [9]. The PWM output is completed with the introduction of an appropriate dead time to the control signals of the inverter switches.

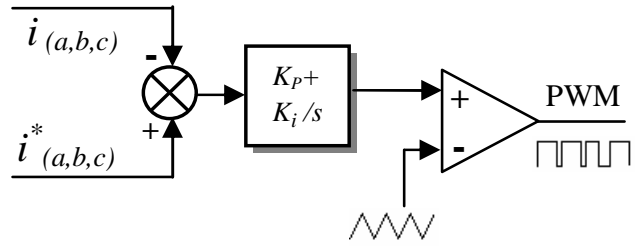

Fig.4 Linear current control technique

\section{THE SIMULATION RESULTS}

The simulation results were carried out under the parameter shown in appendix (A). The simulation is studies in two cases of operation of the PWM rectifier and its control circuit, steady state and transient operation.

\subsection{Steady State Operation}

In these figures, the waveform of ac line phase current $i_{a}$ and respective voltage $v_{a}$ is shown in Fig. (5-a). Also Fig.(5-b) shows the three-phase line currents. The ac line phase current and its reference are depicted in Fig.(5-c). Harmonic spectrum of ac line current is shown in Fig.(5-d) then, the total harmonic distortion has been calculated. Fig.(5-e) shows the dc bus voltage $V_{d c}$ with its reference $V_{d c}$ * where the reference output dc bus is set to $560 \mathrm{v}$. It is observed from these figures that the ac line current is in phase with the supply voltage and make sure the unity power factor at the supply with good result of $T H D$, where it was found $1.4313 \%$. The feedback line current $i_{s}$ follows its reference, also the dc bus voltage $V_{d c}$ is regulated at its reference of set value.

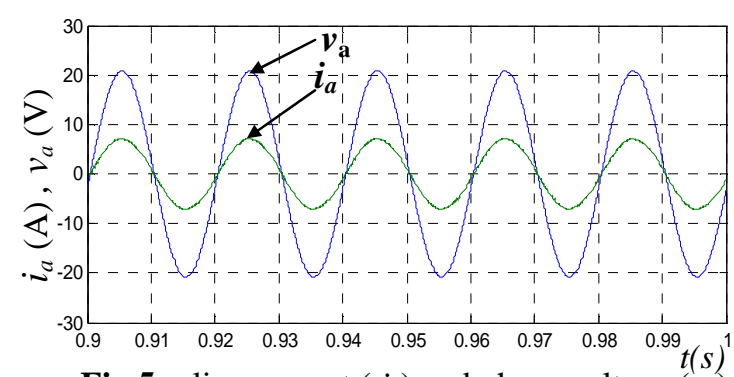

Fig.5-a line current $\left(i_{a}\right)$ and phase voltage $\left(v_{a}\right)$
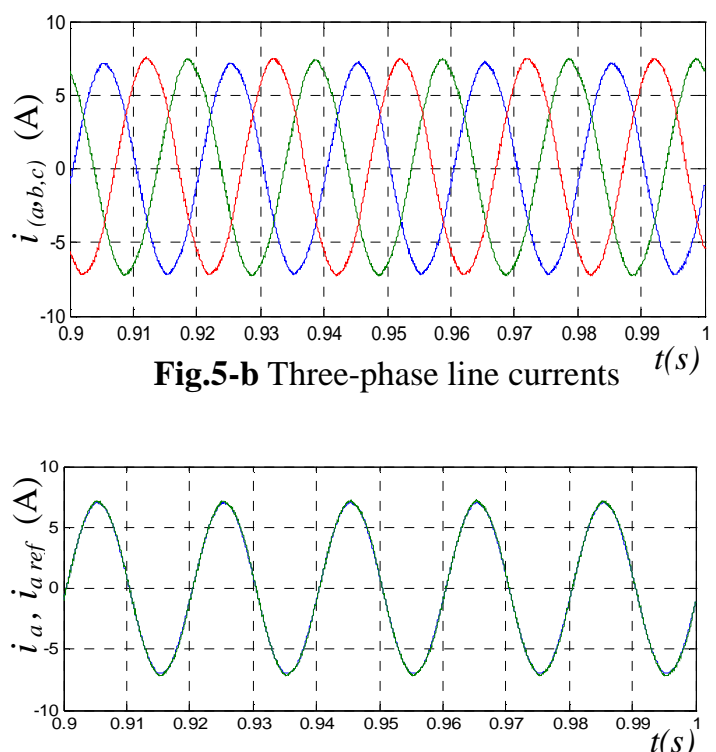

Fig.5-c Actual line current and its reference

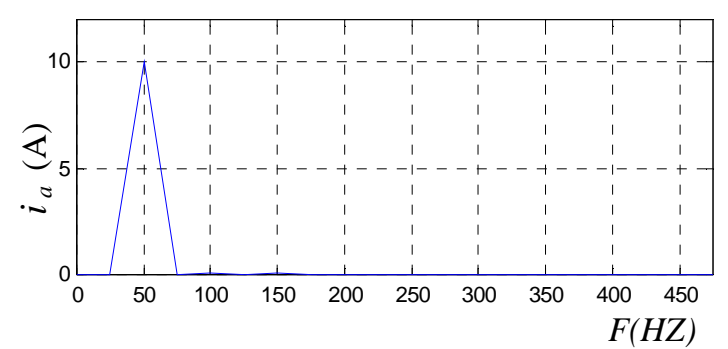

Fig. 5-d Harmonic spectrum of ac line current

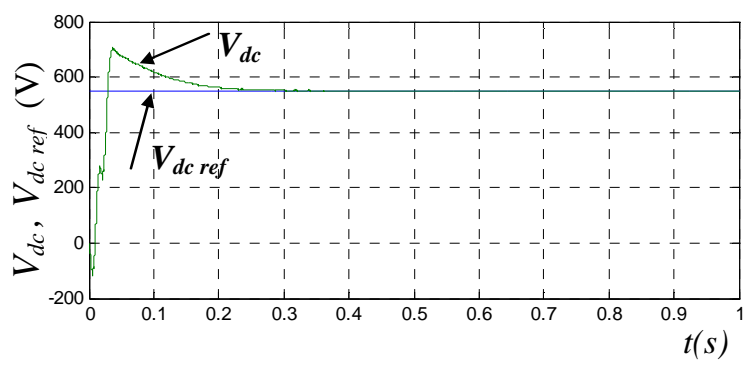

Fig.5-e Actual dc voltage (capacitor voltage) and its reference

Fig.5 Simulation result in case steady state operation 


\subsection{Transient Operation}

In transient operation of PWM rectifier, change of both the resistive load and dc output bus voltage are considered.

\subsubsection{Change the load $(R)$}

Figure 6 shows responses to step changes in the resistive load. The load resistance $R$ was changed from $45 \Omega$ at time $0.9 \mathrm{sec}$. to $25 \Omega$. Fig.(6-a) shows the line phase current $i_{a}$ and the supply voltage $v_{a}$ while the suddenly changing of $\mathrm{R}$ load. The dc bus output voltage $V_{d c}$ and its reference also is shown in Fig.(6-b). From these figures, its notice that the line phase current $i_{a}$ almost in phase with respective voltage $v_{a}$ even with changing of $\mathrm{R}$ load. Also the dc bus output voltage is arrival to the target value after finishing the transient period of suddenly change of $\mathrm{R}$ load.

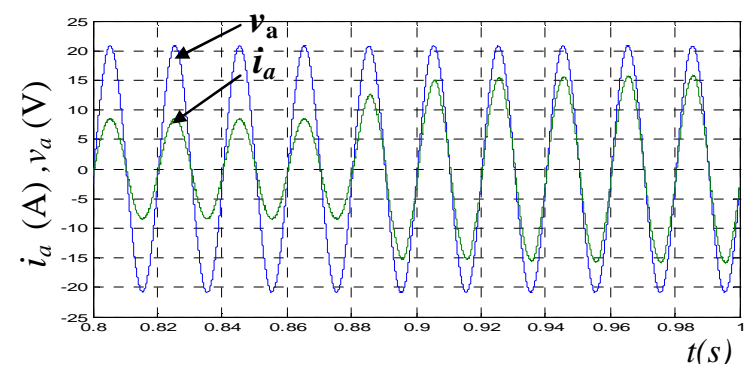

Fig. 6-a The line current $i_{\mathrm{a}}$ and the supply voltage $v_{a}$

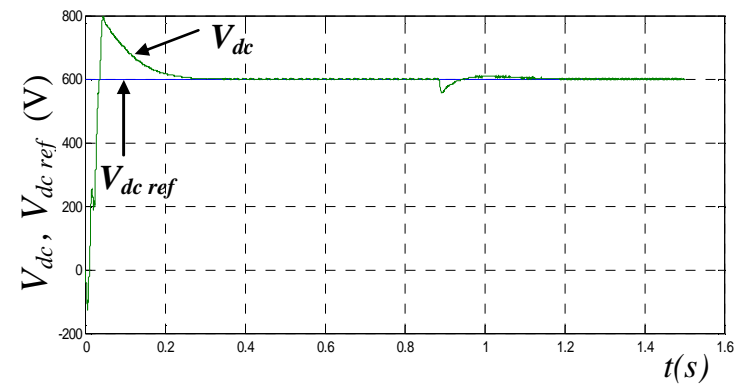

Fig. 6-b The dc bus output voltage $V_{d c}$ and its reference

Fig.6 Simulation result in case step change of resistive load

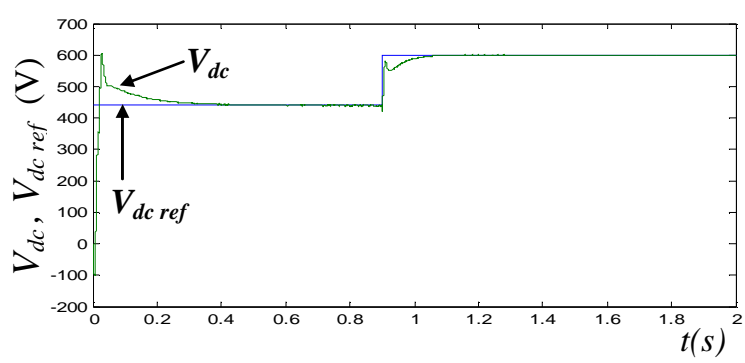

Fig.7-a Step change in dc output voltage $V_{d c}$ and its reference

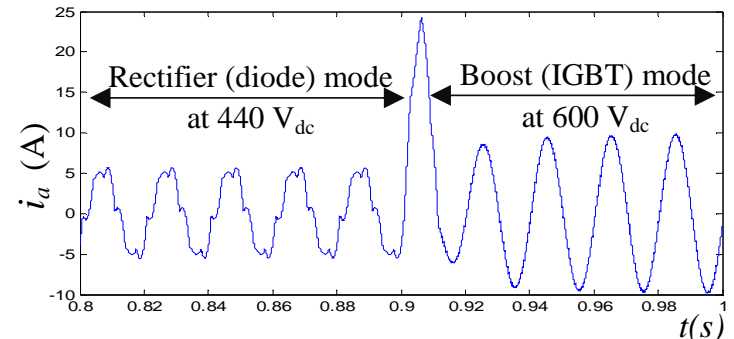

Fig.7-b The line current while step change in dc output voltage

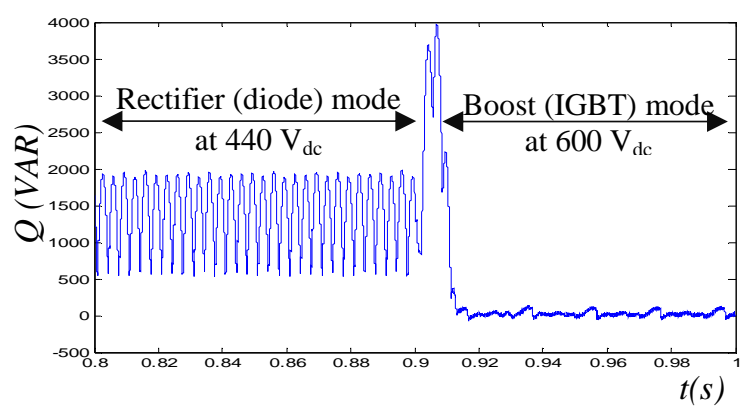

Fig.7-c The reactive power $(\mathrm{Q})$ while step change in dc output voltage

Fig.7 Simulation result in case change of dc output voltage

\subsubsection{Change of DC output voltage}

The reference of dc bus output voltage is changed from $440 \mathrm{~V}$ to $600 \mathrm{~V}$ and the results are shown in Fig.(7). The feedback dc bus output voltage $V_{d c}$ and its set value $V_{d c} *$ is shown in Fig.(7-a) Also the behavior of line current $i_{\mathrm{a}}$ and its respective supply voltage $v_{\mathrm{a}}$ in case changing of dc bus output voltage reference is shown in Fig. (7-b). The reactive power $(Q)$ is obtained (Fig.7-c) while changing from $440 \mathrm{v}$ to $600 \mathrm{v}$ (reverse power flow direction). From this figures, it can be remarked that; when the output dc voltage is $440 \mathrm{v}$ (power flow direction from source to load) the line current is non sinusoidal and the reactive power $(\mathrm{Q})$ is arrival around to 1500 VAR. Otherwise the line current is sinusoidal and the reactive power $(\mathrm{Q})$ is arrival around to zero when the output dc voltage is $600 \mathrm{v}$ (reverse power flow direction).

\section{EXPERIMENTAL TESTS}

Prototype of the PWM rectifier was build and tested in the laboratory. Simplified diagram of the test circuit is depicted in Fig. 8. The power circuit is constructed IGBT's. The necessary feedback signals from the power circuit are obtained by using the halleffect voltage and current sensors. (only two of the three-phase quantities are sensed). Also the voltage and the current isolators sense the DC capacitor voltage and load current respectively. This system is fully controlled by using Digital Signal Processor 
(DSP) and developed under the integrated development environment of MATLAB -

SIMULINK provided by the MATHWORK. The control algorithm of experimental setup generates switching functions, which are the output of DSP and the resulting pulses are gating the IGBT's of the PWM rectifier. Figure (9) shows experimental results for the resistive load condition. Figure (9-a) shows the ac line current (ia) composite with its phase voltage (va). The three-phase line currents is depicted in Figure (9-b). Fig.(9-c) shows the dc capacitor voltage Vdc and its reference Vdc*. From these figures, it is clear that the line current almost sinusoidal and in phase with supply voltage, and the actual capacitor voltage follow its reference.

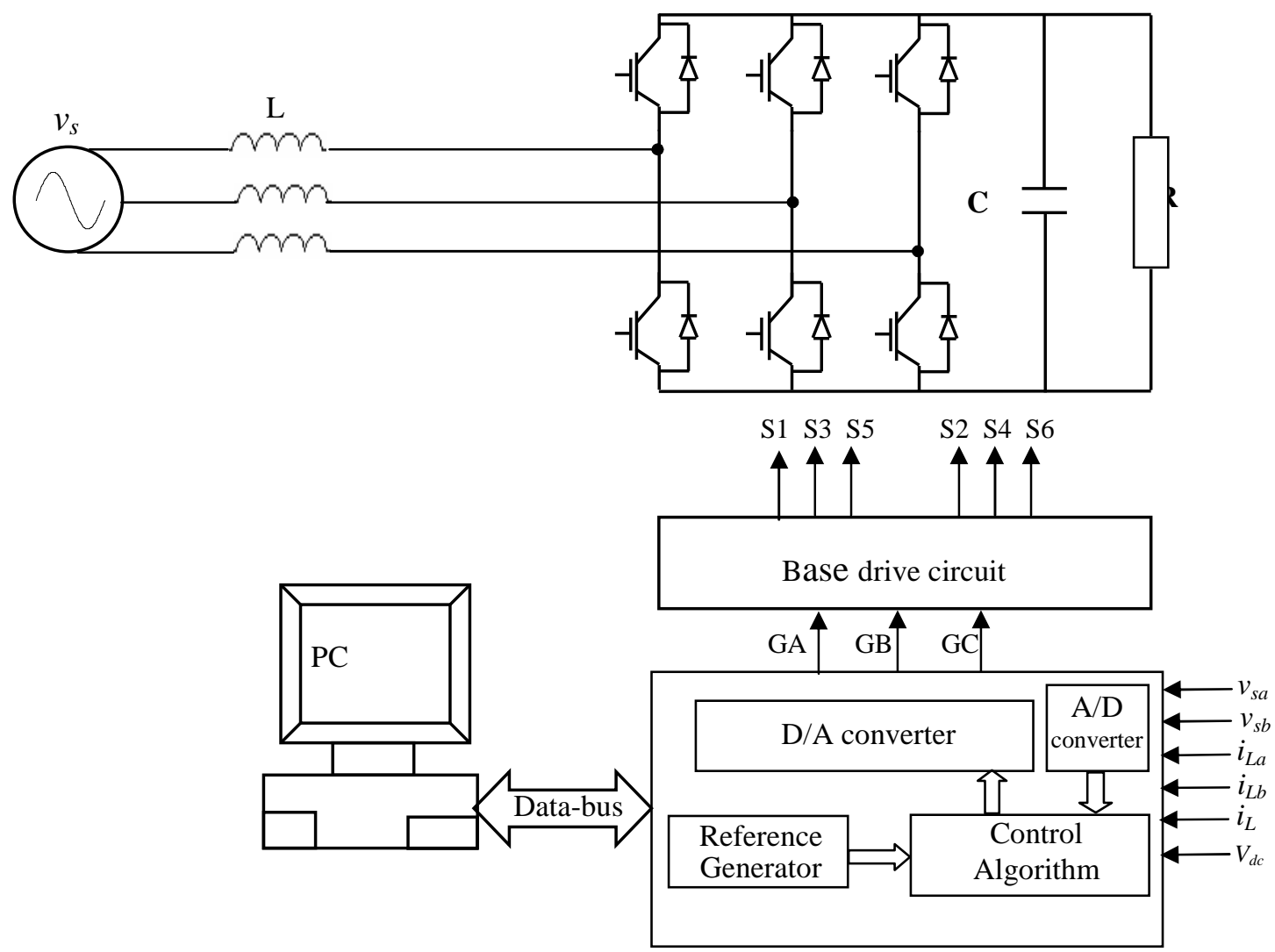

Fig.8 Digital Signal Processing (DSP) system hardware.

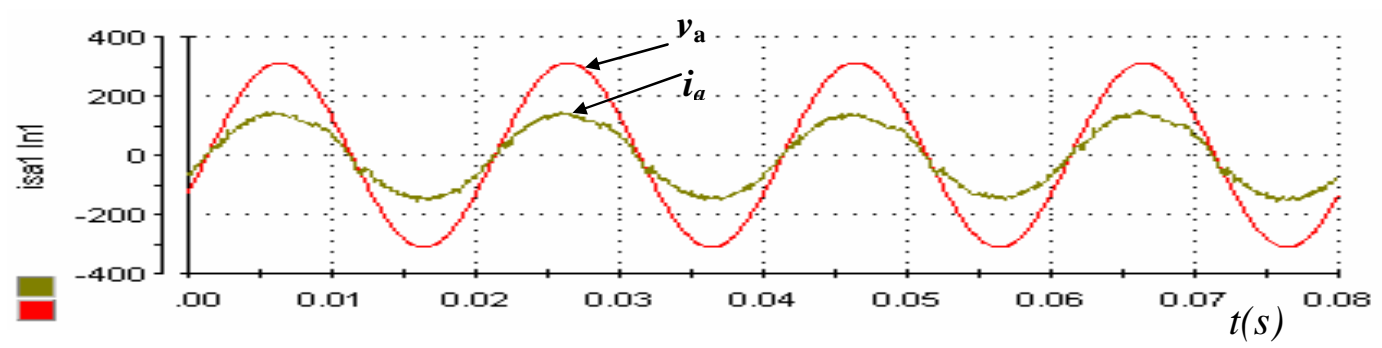

Fig. 9-a Experimental tests; The actual line current $\mathrm{i}_{\mathrm{a}}$ and with supply voltage $v_{a}$

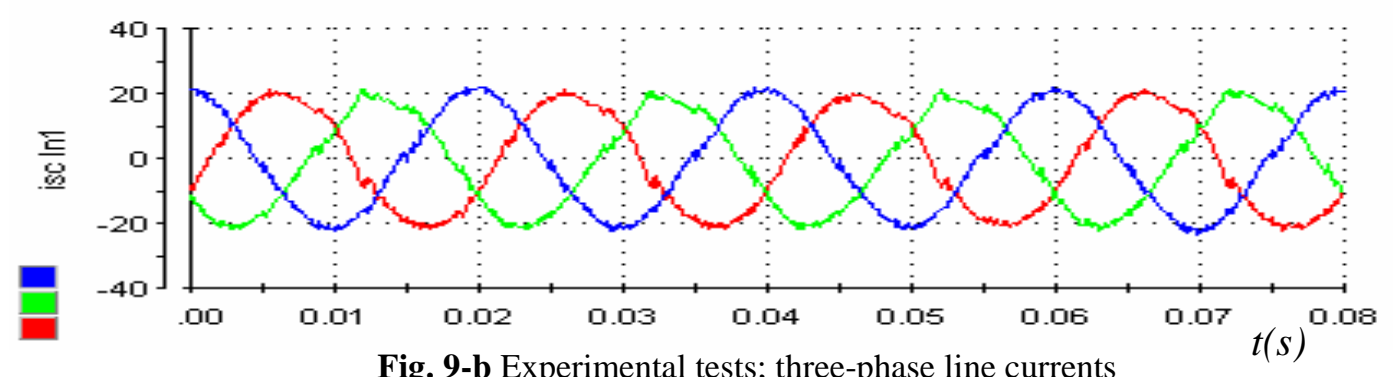




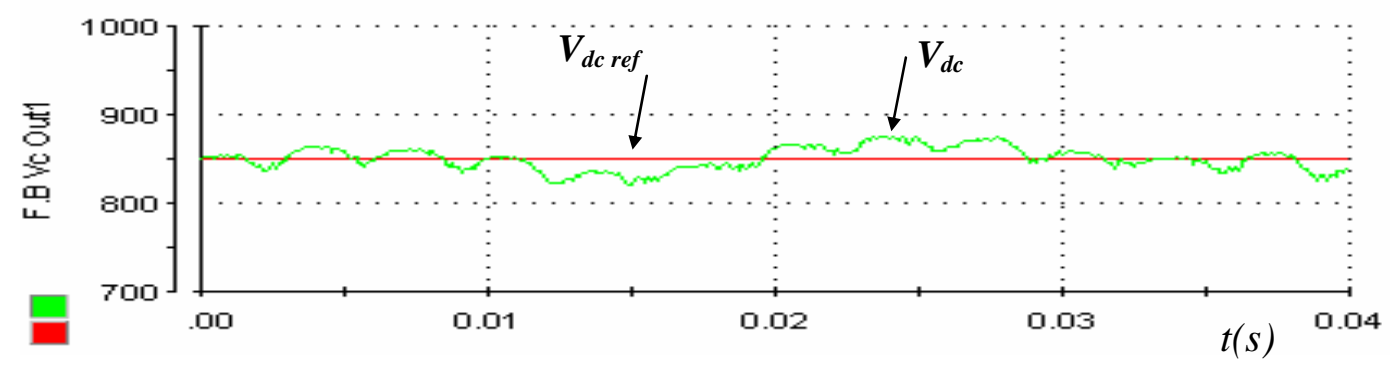

Fig. 9-c Experimental tests; The dc bus output voltage $V_{d c}$ and its reference

\section{CONCLUSION}

In this paper, a three-phase PWM rectifier with control method based on two closed loops has been presented and analyzed. The first loop was dc bus voltage with PI controller, and the second was Dc load current feed-forward loop. The summing output for two loops of control was employed to generate the reference line current of PWM rectifier. The simulation results proved the validity of the proposed control method and feasibility of PWM rectifier. The actual current tracks the desired value without delay; it is robust to the variations of resistance $\mathrm{R}$ This paper verified that PWM rectifier and its proposed control scheme have ability to obtain sinusoidal shaped ac input current, which in phase with corresponding voltage. Then the harmonics in the ac line current has been reduced also the power factor was improved. The paper prove that the three-phase PWM rectifier has a series of advantages, such as low input current distortion, high quality dc voltage, controllable power factor, reduced size-filtering components, which besides are not subjected to power system resonance [4]. An experimental PWM rectifier has been carried out on DSP to explore the advantages and practical implementation with the proposed control strategy. The experimental and simulation results showed that the proposed system has a good performance in the harmonic mitigation and improving the input power factor.

\section{APPENDIX (A)}

The parameters of the three-phase PWM boost rectifier (BR).

$\begin{array}{lcl}\text { Input voltages } & v_{s}=380 \text { volt } \\ \text { BR load resistance } & R & =45 \Omega \\ \text { BR input inductor } & L_{s} & =10 \mathrm{mH} \\ \text { BR capacitor } & C & =750 \mu \mathrm{F} \\ \text { SAF inductor } & L_{f} & =30 \mathrm{mH}\end{array}$

\section{REFERENCES}

[1] K.H. Yiauw and M.S. Khannicke, "Three Phase Active Power Filtering Using Sliding Mode Control", University of Wales, Swansea, UK, 2001.

[2] B.N. Singh, Praveen Jain and Geza Joos, "ThreePhase AC/DC Regulated Power Supplies: A comparative Evaluation of Different Topologies", IEEE Canada 2000.

[3] In-Gyu Park, Sand-Yong Park, and Jon-Keun Park, "An Analysis of Boost Rectifier", IEEE Korea 1991.

[4] Rolando P. Burgos, Eduardo P. Wiechmann and Jose R. Rodriguez, "A simple adaptive fuzzy logic controller for three-phase PWM Boost rectifiers”, IEEE 1998.

[5] Cedric Worthmann and Greg Diana, "Neural network current controller for a boost rectifier", IEEE South Africa 1998.

[6] J. Fernando Silva and J. F. Martins, "Space vector alfa beta current regulator for sliding mode controlled unity power factor PWM rectifiers", IEEE Portugal 1998.

[7] Dawei Gao and Xiaorui Sun, "A Shunt Active Poer Filter with Control Method Based on Neural Network", Department of Electrical Engineering, North China Electric Power University Qinghe, Beijing, P.R. China, IEEE 2000.

[8] B. T. Ooi, J. C. Salmon, J.W. Dixon, and A. B. Kulkarni, "A three-phase controlled-current PWM converter with leading power factor," IEEE Trans. Ind. Applicat., vol. 23, pp. 78-84, Jan./Feb. 1987.

[9] T. Takeshita, T. Kobayashi, and N. Matsui, "A scheme of power source voltage sensorless threephase PWM ac/dc converter," Trans. IEE Jpn.,vol. 114-D, no. 12, pp. 1211-1219, 1994.

[10] T. Noguchi, H. Tomoki, S. Kondo, and I. Takahashi, "Direct power control of PWM converter without power-source voltage sensor," IEEE Trans. Ind. Applicant., vol. 34, pp. 473479, 1998.

[11] T. Ohnuki, O. Miyashita, P. Lataire, and G. Maggetto, "A three-phase PWM rectifier without voltage sensors," in Proc. EPE'97 Conf., 1997,pp. 2.881-2.886. 